\title{
Дизайн печатных СМИ: эволюция понятия «КОМпОзИция»
}

\author{
Станислав Галкин
}

Будущее печатных СМИ, в частности газет, вызывает большие опасения. Композиция периодического издания является одним из важных факторов визуализации контента номера газеты или журнала. В статье на основе анализа исследований теорий композиции делается вывод, что журнал и газета в настоящее время имеют так мало общего, что рассмотрение композиции как единого целого в различных типах изданий нецелесообразно.

Ключевые слова: газета и журнал, композиция и структура печатных СМИ, комплекс, материал, полоса.

(C) Галкин Станислав Илларионович кандидат филологических наук, доцент кафедры фотожурналистики и технологий СМИ факультета журналистки МГУ имени М.В. Ломоносова (г. Москва, Россия), kafedrafoto208@gmail.com

\section{Две реперные точки}

Выражение «визуализация вербального контента» стало крылатым. Один из возможных вариантов перевода на доступный для любого читателя язык - «понимание содержания текста». Однако непонятно, о каком тексте идет речь: о содержании номера или о статьях о школьном образовании в нескольких выпусках издания, или о комментарии/репортаже с конкретного футбольного матча. Помочь прояснить данный вопрос должно исследование такого явления, как композиция.

Композиция - аспект, один из срезов внешней формы, которая есть объект деятельности дизайнера. Внешняя форма периодического печатного издания насчитывает до 8-10 уровней: от элемента до издания. Эти компоненты воспринимаются по-разному, например, текст и иллюстрация, заголовок и текст, спуск и текст. Идаже кажущиеся (предполагаемые) однородными комплексы могут иметь трудно сравниваемый вид: текст обычный (черные буквы на белом фоне), текст на подложке (на цветном фоне), текст на выворотку (белое на темном). Читателя в отличие от дизайнера интересует содержание, т.н. контент, а изменяя фон от белого (текст занимает 12-13\% площади) до черного (в выворотке около 90\% черного), дизайнер вносит 
искажение в восприятие содержания, а в конечном счете - и в сам контент.

Если же проанализировать исследования композиции СМИ, то следует обратить внимание на две реперные точки. Первая: «Содержание газеты определяет композицию - построение - каждого из ее номеров <...> Газетный номер должен представлять собой органичное целое. Основой номера является его план... Задача этого плана - обеспечить целеустремленность и вместе с тем разносторонность номера, материалы которого должны освещать самые разные вопросы и темы, представляющие интерес и для всего круга читателей газеты, и для различных групп читателей, с их особыми интересами <...> Композиция номера и призвана обеспечить единство противоположностей - выполнение этих подчас противоречащих друг другу задач» (Попов, Гуревич, 1967: 206).

В дефиниции речь идет о двух объектах: газете (комплекте номеров) и номере. Для исследователя (например, историка), работающего с подшивкой издания, все выглядит так, как описано в определении. Однако следует заметить, что утверждение: «содержание определяет композицию» спорно, потому что сначала необходимо прочитать текст и только после этого придет понимание контента. Кроме того, визуализация вербальной информации начинается с заголовков, затем следует изучение текста отдельного материала. То есть осознание, «познание» содержания вторично (вспомните: материя первична в гносеологическом смысле).

Теперь о сути дефиниции: композиция как построение. В словаре С.И. Ожегова дается такое определение композиции: «1. Строение (во 2 знач.), соотношение и взаимное расположение частей »2. Словарь отсылает нас ко второму значение слова «строение»: «Взаимное расположение частей, составляющих одно целое, структура [курсив наш. - С.Г.]»³. Иначе говоря, компо- зиция газеты, определяемая как построение каждого из номеров, представляет собой структуру каждого из номеров, которая, в свою очередь, есть аспект внутренней формы. Если обратиться к Гегелю, то нетрудно обнаружить тождественность содержания и внутренней формы. Читатель приходит к содержанию (внутренней форме) через внешнюю форму, то есть композицию.

В учебнике «Оформление периодических изданий» И.Н. Табашников (автор главы о композиции) наметил новый подход к пониманию внешней формы СМИ. «В каждом виде искусства композиция проявляется специфически. Оформлению периодических изданий свойственна композиция, которая объединяет по законам гармонии текстовые колонки, иллюстрации, заголовки и другие графические элементы на плоскости каждой страницы, в пространстве всего номера издания и вместе с тем создает необходимый порядок восприятия содержащейся в этом номере информации» (Киселев (ред.), 1988: 97).

Это вторая реперная точка в эволюции понятия «композиция». Здесь речь идет о композиции как аспекте внешней формы на трех уровнях: 1) комплексы (текстовый, иллюстрационный, заголовочный) $\left.{ }^{4}, 2\right)$ полоса (страница), 3) номер. И композиция данных комплексов (элементов), а также полосы рассматривается как объединение их на плоскости, а номер - объединение страниц в пространстве. В теории искусства книги (термин А.А. Сидорова) говорят о пространственно-пластическом анализе произведений изобразительного искусства (Гончарова, 1990: 300), о процессе пространственно-изобразительного характера при оформлении изданий художественной литературы (Гончарова, 1990: 379) и т.п. Наиболее интересно с точки зрения оформления периодических изданий следующее заключение: «Так, материальная конструкция книги, предлагая ту или иную разверстку поверхностей (термин 
В.Н. Ляхова) становится объектом композиционно-пространственного решения» (Гончарова, 1990: 378). То есть пространственный аспект внешней формы не является композицией в том значении, которое трактуется как объединение неких объектов на плоскости. «Решение задач композиционных не заменяет задач конструктивных, ибо всякое изобразительное, композиционное пространство возникает в пределах формы конструктивной» (Гончарова, 1990: 379).

Если вновь вспомнить о внешней и внутренней форме (в данном случае книги), то конструктивная форма - срез, аспект внутренней формы. «Конструкция <...> 1. Состав и взаимное расположение частей какого-н. строения, сооружения, <...>, а также само строение, сооружение» 5 . Только здесь речь идет о структуре внешней формы - книге (экземпляре книги).

Подводя некоторые итоги анализу разновидности книжной композиции, следует процитировать следующее высказывание Н.А. Гончаровой (1990: 379): «В различных видах изданий возможно преобладание либо композиционного, либо конструктивного». И это не только связано с функцией, назначением книги (художественное произведение, научное издание), но также зависит от субъективного фактора: кто будет оформителем книги. Если ее иллюстрирует художник, то необходимо говорить об искусстве книги (Галкин, 2010: 27). Когда же в главной роли выступает технический редактор (типограф, по выражению Я. Чихольда), то речь идет о типографическом оформлении (Галкин, 2010: 29-30). Некоторые журналы (научные, литературно-художественные) имеют много схожих внешних признаков с книгой. Но массовые журналы, а тем более газеты имеют свои, только им присущие черты (Галкин, 1984: 152).

В учебнике «Оформление периодических изданий» дается определение одного вида композиции, единой и для журналов, и для газет. Итак, «композиция <...> объединяет» комплексы оформительских элементов «на плоскости каждой страницы» (Киселев (ред.), 1988: 97). В дефиниции Попова и Гуревича (1967: 206) речь идет о композиции номера и только после этого говорится о композиции полосы: «Каждая из полос имеет свой, особый план, свою композицию. Но одновременно каждая полоса - часть целого газетного номера [курсив наш. - С.Г.]» В учебнике 1988 г. - обратный порядок рассмотрения композиции, «которая объединяет» комплексы «на плоскости каждой страницы, в пространстве всего номера издания [курсив наш. - С.Г.] (Киселев (ред.), 1988: 97).

В то же время и в первом, и во втором учебниках композиционное построение связано с заботой о читателе: «Задача этого плана [номера] - обеспечить целеустремленность и вместе стем разносторонность номера, материалы которого должны освещать самые разные вопросы и темы, представляющие интерес и для всего круга читателей газеты, и для различных групп читателей, с их особыми интересами» (Попов, Гуревич, 1967: 206), «композиция <...> создает необходимый порядок восприятия содержащейся в этом номере информации» (Киселев (ред.), 1988: 97).

Действительно, читатель листает номер газеты/журнала, просматривает заголовки и иллюстрации и останавливается на заинтересовавшем его тексте (материале). Итак, редакция делает набросок плана номера, исходя из данных сетевого графика, затем на планерке составляется план номера из конкретных материалов в виде плана соответствующих полос, которые верстаются (по возможности) согласно плану, то есть номер создается так, как описано в учебнике 1967 г. Однако визуализация вербального контента происходит в другом порядке: сначала поверхностное знакомство со страницами, затем переход к конкретным 
публикациям. Читатель, как правило, не оценивает номер газеты (тем более журнала) в целом, номер воспринимается как мозаика (но не пазлы), а полосы - как узоры в калейдоскопе.

Говоря о восприятии информации следует различать точку зрения профессионалов-художников и читателей, практику дизайна и исследования психологов, теоретиков искусства и эстетики. Исследователи искусства книги вынуждены обращаться в поисках наиболее точного выражения своих мыслей к таким источникам, которые имеют мало отношения к печатным изданиям вообще и к современной книге в частности. Так, Н.А. Гончарова (1990: 334) пишет: «Любопытно, что к числу признаков прекрасного Аристотель причислял меру обозримости, утверждая, что ни чрезмерно малое, ни чрезмерно большое не могут мыслиться как прекрасное, ибо затруднительны для восприятия обозревающих». Если исходить из смысла этой сентенции, то непонятно, как оценивать, с одной стороны, прелесть марок (объект поклонения филателистов), с другой - фолиантов (предмет гордости библиофилов).

Сейчас очень популярен карманный формат ${ }^{6}$. И он используется не одно столетие (Галкин, 2010: 32). В отношении периодических изданий следует обратить внимание на двуформатность журналов Cosmopolitan, «Караван историй» и др. Они перешли на малый формат для удобства читательниц: журнал такого размера помещается в небольшую сумочку. Что касается изменения форматов газет, можно вспомнить переход на таблоидный формат воскресного выпуска The Times в конце 2000 гг. и всех выпусков «Ведомостей».

\section{Искусство оформления... газеты?}

Возвращаясь к теории книжного искусства, можно обратить внимание на факт объединения различных видов деятельности, имеющих очень непохожие основы функционирования. «Мы должны взять в расчет шесть вещей [факторов. - С.Г.] при подготовке [при структурировании или при создании внешней формы. - С.Г.], когда мы пишем, фотографируем, моделируем, гравируем или работаем самыми разными средствами, которыми выражается идея в графической форме: размещение различных элементов (месторасположение), масса или вес с учетом их сбалансированности, близко лежащую к этому композицию значимости [курсив наш. - С.Г.], линейную композицию, цветовую композицию, композицию перспективы - довольно характерное напутствие художникам» (Гончарова, 1990: 301).

К такому заключению Н.А. Гончарова пришла, потому что начала свою книгу с главы «Общие сведения о композиции». И отметив, что древние греки считали основой мирового порядка гармонию: «Гармония - общее состояние, композиция средство достичь его» (Гончарова, 1990: 294), автор решила взять термин «композиция" у древних римлян, что никого не должно смущать. Латинское «слово "композиция" - составление, соединение частей, приведение их в порядок - в первоначальном значении имело более широкий смысл: оно выражало представление о сторонах, частях, при соединении которых образуется единство» (Гончарова, 1990: 303). Довольно логичное построение, приводящее вскоре к выводу о главенствующей роли композиции в искусстве (в самом широком значении этого слова). Однако напрашивается возражение: если в книге как объекте искусства, то есть в создаваемой художником наряду с автором текста книге, композиция как одна из категорий эстетики играет одну из ведущих ролей, то отнести к искусству оформление сборника статей, напечатанного на ризографе, наверное, будет не совсем корректно. И, соответственно, научные журналы, освещающие как исследования тождественности, 
так и гуманитарные темы, представляют предмет эстетики только для профессионалов-типографов и дизайнеров.

Вместе с тем называть печатные издания, начиная с газет и заканчивая книгами, продуктами деятельности дизайнеров было в те годы практически невозможно. А вот говорить о журналах и газетах, оформляемых по законам «марксистско-ленинской» эстетики, даже поощрялось. Поэтому своего рода преамбула определения понятия «композиция» в учебнике «Оформление периодических изданий» предлагает более широкое толкование термина, чем необходимо для объяснения функций, свойств, средств композиции газеты и журнала. «В каждом виде искусства композиция проявляется специфически. Оформлению периодических изданий свойственна композиция, которая объединяет по законам гармонии <...> графические элементы на плоскости каждой страницы...[курсив наш. С.Г.]» (Киселев (ред.), 1988: 97).

Первое впечатление от определения это конспект работы Н.А. Гончаровой в семи строках. Однако если посмотреть «расшифровку» дефиниции (детализация дается сразу после объяснения понятия, и ей уделяется 17 страниц), то становится понятным оригинальность, «особость» подхода автора главы. Вот, например, что написано о таком свойстве композиции, как гармоничность. «Целостная, хорошо продуманная в функциональном и эстетическом отношениях композиция периодического издания обладает несомненной образностью. Только эта образность особого рода, отличающаяся от образности в "чистых" видах искусства - живописи, графике, скульптуре и т.п. По своей природе образность внешней формы газет и журналов примерно такая же, как в архитектуре и дизайне <...> Форма в этих искусствах стремится эмоционально передать "дух" вещи, здания - их функциональное предназначение. Характер (динамичный - ста- тичный, легкий - основательный, простой сложный и т.д.). Композиция периодических изданий еще до знакомства читателей с содержанием номера способна на эмоциональном, чувственном уровне информировать их о типологических аспектах издания - его назначении, адресованности определенной аудитории, о характере публикуемых материалов - деловом или официальном, торжественном или веселом, полном динамики или спокойном» (Киселев (ред.), 1988: 38)7. Такое разъяснение понятия композиции газет и журналов через образность в архитектуре не совсем корректно. Речь идет не об образе, а скорее об образце, шаблоне. Своеобразном блочном ${ }^{8}$ и даже панельном построении, конструировании полос.

Образец ожидания - Erwartungsmuster понятие, применявшееся в ГДР (Schröder, 1969). Оформление какой-либо рубрики (раздела), как правило, постоянно. За определенной темой закрепляется полоса, название и шрифт (пиктограмма или инфографика) - например, в разделах «Злоба дня» и «Срочно в номер» в «Московском комсомольце». Несколько лет сохраняется ширина колонки и структура материала «Вопрос дня» в «Комсомольской правде», подборки non-stop в «Московском комсомольце» и т.д. Все это в моделировании (художественном проектировании) газеты и журнала называется стандартными операциями (или стилями) оформления.

Подобное построение полос рассматривается в учебнике «Производство и оформление газеты» как «устойчивый тип» газетной композиции. Но в то же время устойчивость не означает жесткость. Композиция должна быть гибкой, утверждают авторы книги (Попов, Гуревич, 1967: 207). Жесткая композиция была характерна для ежедневных изданий 1950 гг. В конце 1950 и 1960 гг. тематика общеполитических газет расширилась, появилась необходимость закреплять рубрики не только за опреде- 
ленными страницами, но и за днями недели, так как некоторые разделы публиковались один-два раза в неделю и даже раз в месяц. Так возникли т.н. сетевые графики, то есть графики публикации основных разделов, рубрик и тем, привязанных к определенным дням недели. Сетевые графики представляли структуру газеты.

Графикам сопутствовали стандартные операции оформления. Появились стандартные макеты. И если на блочных макетах, превратившихся сейчас в шаблоны полос, присутствовали только постоянные комплексы (титульный, колонтитулы, колонцифры, выходные сведения, постоянные - появляющиеся в каждом номере - рубрики, плашки=подложки), то макеты-эталоны демонстрировали варианты «образцов ожидания», то есть детальное оформление той или иной темы на данной полосе. Эталонный макет - это образец ${ }^{9}$ полосы, где все настоящее, начиная с рисунка, начертания и кегля шрифта и заканчивая размером, планом (крупным, средним, общим) и в какой-то мере сюжетом иллюстрации. Но контент текстов и заголовков не имеет никакого отношения к содержанию газеты/журнала за исключением тех случаев, когда для макета-эталона используется «шпек» вышедших номеров. В то же время эталонная страница верстается на макете = шаблоне (блочном макете) этой полосы. И тут дизайнер при разработке проекта издания сталкивается с дилеммой, как при единстве стиля издания добиться оригинальной подачи различных рубрик и разделов.

Подобная проблема возникает прежде всего при работе с большим форматом - A2. Дело в том, что в таких газетах на странице публикуется от двух до 11 материалов («Московский комсомолец»). На полосе АЗ заверстывается от одной до пяти публикаций («Комсомольская правда»). Надо заметить, что для четырех материалов при использовании прямой верстки офор- митель имеет дело с девятью вариантами композиций, для пяти их число увеличивается до 21 и т.д.

Во второй половине 1960 гг. редакции региональных и центральных газет внедряли и «обкатывали» сетевые графики, то есть занимались упорядочением структуры издания. Во всех центральных газетах использовались закрепленные стили оформления. «Известия», «Комсомольская правда», «Правда», «Труд» демонстрировали верстку по стандартным макетам. Практика моделирования нашла свое отражение в теории: в 1970 гг. были успешно исследованы проблемы художественного проектирования газеты, включая модульные сетки ${ }^{10}$. И вторая половина 1970 гг., а также начало 1980 гг. прошло под знаком массового внедрения стандартных макетов в практику городских и районных газет России. Объяснялось такое явление просто: местные газеты переводились на централизованный выпуск, фотонабор и плоскую офсетную печать. Подобный технологический процесс означал неполнокодовый (неформатированный) набор (набивку) текстов редакции, монтаж (верстку) полос и печать номера в межрайонном (г. Мытищи), областном полиграфическом комбинате (полиграфкомбинат «Московская правда») и т.п. Выпускающий делал макеты в центре выпуска газет (один выпускающий на два-три издания, то есть работа над четырьмя-пятью страницами в день). Кроме того, он контролировал монтаж, корректуру, подписывал номер в печать. Облегчить работу выпускающего и были призваны стандартные макеты плюс модульная сетка. Но если в Подмосковье и в Ленинградской области возникающие проблемы решались более или менее успешно, так как переходили на новые технологии постепенно, то во Владимирской области сложилась ситуация, когда разработанные на кафедре техники газетного дела и средств информации факультета журналистики МГУ име- 
ни М.В. Ломоносова стандартные макеты, предусматривавшие верстку на пять или шесть колонок, не понравились технологам Владимирского полиграфического комбината, и газеты волевым решение перевели на четырехколонную верстку, актуальную до Великой Отечественной войны. И если в редакциях, где были опытные оформители, смогли приспособиться к новым условиям, то в других пустили дело на самотек, отдали в руки полиграфистов, только начавших осваивать фотонабор и монтаж.

Ко второй половине 1980 гг., казалось бы, накоплен огромный эмпирический материал (Республика Адыгея, Владимирская, Ленинградская, Московская, Челябинская области и другие регионы, где местные газеты освоили новейшие технологии выпуска газет). Пройден классический путь в исследовании: практика (сетевые графики плюс стандартные операции оформления плюс стандартные макеты) $\Rightarrow$ теория моделирования газеты $\Rightarrow$ внедрение этой теории в практику местных газет. Однако понятие композиции трактуется по-прежнему с точки зрения "высокого» искусства, к ней применяются эстетические категории и т.п. почти так же, как и в книжном искусстве. Дело в том, что модель, или художественный проект, представляет собой систему, которая есть формализованный образец структуры (внутренней формы) и ее отражения в композиции (внешней форме) газеты. И если рассматривать отдельные компоненты внешней формы, то окажется, что они непременно закреплены за какой-то рубрикой, которая, согласно сетевому графику, появляется в определенные дни недели на конкретной полосе. Большинство заголовков размечается одинаково. Проявляются же (в проекте) стили оформления заголовков, текстовых колонок и т.д. на эталонных макетах полос.

То есть в модели нет главной определяющей содержания, первосущности номера газеты ${ }^{11}$ - материала (Галкин, 2012). Он, разумеется, всегда является частью раздела издания, но читатель далеко не всегда отслеживает все материалы определенной рубрики на протяжении, скажем, недели. Когда разрабатывали теорию моделирования (на основе практики), в первую очередь, конечно же, имели в виду интересы читателя: подборку о делах на даче он с удовольствием (и с пользой для себя) прочитает в пятницу, о соблюдении графика сна и отдыха в понедельник (или во вторник, если газета в понедельник не выходит). Для журналистов моделирование как инструмент научной организации труда имел большое значение. Но и исследователи, и журналисты-практики постоянно забывали, что читатели в 1970 гг. посвящали чтению газет не больше 20 минут в день. И читали только то, что их интересовало. Выражение «газета живет один день» неверно: «Московский комсомолец» в 2019 г. отметил 100-летний юбилей. Один день живет номер. Причем в нем для конкретного читателя свой материал. Читатель бегло просматривает первую полосу, переворачивает номер и то же самое проделывает с четвертой, последней полосой (в подавляющем большинстве газет 1980 гг.). Затем на внутренних полосах ищет нужный материал, в котором под определенной рубрикой (если она есть) мгновенно «прочитывается» (визуализируется) фото (если оно было). Затем происходит быстрое знакомство с содержанием заголовка. И когда эти два комплекса - иллюстрационный и заголовочный - встают в ассоциативный пазл раздела, читает текст.

\section{Композиция или структура}

Дизайнер, верстая полосу (основу композиции по учебнику 1988 г.), сначала форматирует текст материала (шрифт, выключку, ширину колонки), затем оформляет заголовок ${ }^{12}$. И после, как минимум, пяти-шести операций с текстом и заголовочным комплексом ставится фото. То есть 
верстальщик, руководствуясь макетом дизайнера, каждый день создает новую композицию каждой полосы каждого номера. При этом учитываются и отражаются на данной странице особенности эталонных полос.

Однако повторить композиционную схему эталонного макета даже в четырехполосной ежедневной газете невозможно, если только не подгонять все материалы и комплексы, из которых они состоят, под определенный объем, заданную структуру, что, как показала практика, невозможно $^{13}$. Даже на уровне эскизного графического макета можно установить три уровня композиции (одной из сторон внешней формы): 1) взаиморасположение простых комплексов в составных (иллюстрация и заголовок, иллюстрация и текст и т.п.); 2) взаиморасположение комплексов в материале (например, открытая или глухая верстка заголовков, иллюстраций); 3) взаиморасположение материалов на полосе, которое имеет и такую характеристику, как конфигурация материалов. «Порядок восприятия в <..> номере информации» [структура номера - это, повидимому, другая композиция, «которая объединяет по законам гармонии текстовые колонки, иллюстрации, заголовки и другие графические элементы ${ }^{14}$ на плоскости каждой страницы, в пространстве всего номера издания... [курсив наш. - С.Г.]» (Киселев (ред.), 1988: 97). Данное положение действительно для издания, насчитывающего четыре, шесть, восемь полос со стандартными макетами (шаблонными и эталонными) для каждой полосы.

Кроме того, возникает вопрос, почему и где, в каких изданиях на плоскости страницы, по законам гармонии, объединяются колонки, заголовки и иллюстрации? Рассмотрим, что в контексте приведенного определения говорится о таких средствах композиции, как ритм и метр. «Ритм и метр понятия взаимосвязанные, означающие, однако, различные степени сложности и вариантности чередования.

Метр - это простой повтор аналогичных элементов. В периодическом издании примерами метрического повтора являются идущие одна за другой страницы, строки текстового набора, стандартные колонки <...> Замечено, что если повторяется много одинаковых элементов, то создается впечатление монотонности, усыпляющего движения...

Живость, динамику придает композиции ритм. Ритмические чередования более сложны, они дополняют метрические повторы и, как правило, на них основываются <..> Ритм тесно связан с такими средствами композиции, как пропорции, симметрия, контраст» (Киселев (ред.), 1988: 108).

Разговор о ритме и метре в учебнике «Оформление периодических изданий» начинается со ссылки на работу Е.Б. Адамова «Ритмическая структура книги» (1974)15, следовательно, автор главы о композиции периодических изданий опирался на труды исследователей искусства книги. И подобный факт не является свидетельством приспособления к предмету анализа «удобной» теории. Это свидетельство того, что оформление журналов ближе к книжному, чем к газетному. В книге, за исключением словарей, сборников стихов и других подобных изданий, каждая страница есть комплекс графических элементов. В журналах чаще, чем в книгах, можно встретить полосу, где разверстан материал целиком и даже подборка заметок. В классической же газете формата A3 и A2 постановка материала на полосу, а тем более на разворот до 1990 гг. было явлением исключительным, если не считать официоз (отчеты со съездов, сессий, пленумов и т.п.).

Следовательно, существуют две композиции периодических изданий: журнальная (или книжно-журнальная) и газетная. Композиция журнала может быть определена таким образом: «В сложных по структуре 
изданиях, как правило, многостраничных, составные комплексы объединяются далее в подсистемы <...> В журналах - это разделы, или мегарубрики, объединяющие материалы нескольких разворотов. В зависимости от типа журнала и его конструкции их может быть от пяти и более» (Волкова, Газанджиев, Галкин и др., 2013: 70). И именно композиционное единство полос и разворотов создает гармоничную композицию номера журнала и комплекта номеров за какой-то период.

Газетная композиция - объединение на полосе материалов (которые состоят из комплексов), создающих композицию номера. Ей тоже присущи в какой-то мере такие свойства, как гармоничность (но не образность), стилистическое единство, но не такое, как в журналах. Что же касается средств композиции, то они применимы к характеристикам, присущим всем печатным изданиям - например, пропорциональность форматов.

При этом современные российские газеты используют четыре (пять) стандартных форматов A2, A3, A4 плюс близкие к B2 и В3 (таблоид). Последний формат применяется для газет Metro, «Твой день», «Жизнь», «Желтая газета». У журналов почти 30 стандартных форматов, у книг - почти 60. Соотношение сторон в формате A - 1:1,414, В2 - 1:1,414, а вот популярный в книжном деле формат условного печатного листа дает соотношение $1: 1,66$. Если взять соотношение ряда Фибоначчи, то получатся пропорции от $1: 1$ и 1:2, далее $2: 3(1: 1,5)$, 3:5 (1:1,66), 5:8 (1:6), 8:13 (1:1,625) и т.п. То есть разброс пропорций, если продолжать идти по ряду Фибоначчи, будет большим, но изменяться будут только сотые и тысячные доли.

Такой же разброс в количестве колонок на странице печатного издания. У подавляющего большинства книг набор осуществляется на всю ширину полосы, реже на две колонки (словари, стихотворные сборники и т.п.). В журналах даже малого формата нормой является разверстка на две колонки, в изданиях большего формата было три, реже четыре колонки. В газетах формата A4 преобладала верстка на 3-4 колонки, в АЗ - на 5-6 (редко на 4) столбцов, в А2 от 6 до 10 колонок (10 колонок демонстрировала «Вечерняя Москва» в 1960-1980 гг.). То есть всего два признака (но основополагающих) являются определяющими в композиции печатных изданий, показывая различия между слагаемыми композиции газеты и журнала. В первом случае это: комплексы (заголовочный, текстовый, иллюстрационный) $\Rightarrow$ материал $\Rightarrow$ полоса. Во втором рассматриваем: комплексы (блоки) - полоса и разворот - материал (несколько страниц) $\Rightarrow$ номер.

\section{Примечания}

1 Уровни внешней формы в газете: 1) элемент, 2) комплекс элементов, 3) материал, 4) подборка, 5) полоса, 6) разворот, 7) тетрадь, 8) номер, 9) комплект номеров (подшивка), 10) издание.

2 Ожегов С.И. Словарь русского языка. М.: Рус. яз., 1984. С. 256. Во втором издании учебника В.В. Попова, С.М. Гуревича композиция рассматривается под таким же углом зрения.

3 Там же. С. 688.

4 Термин «элемент» применительно к комплексам взят из теории книжного оформления. См., напр., труды В.Н. Ляхова и др. 
5 Ожегов С.И. Указ. соч. С. 258.

6 «Недаром существует термин - карманное издание, или "книга в руке", как говорили немецкие издатели» (Гончарова, 1990: 333).

7 Можно понять, откуда взялись аналогии композиции периодических изданий с архитектурой. В книге «Производство и оформление газеты» сказано: «Подобно архитектору, который разрабатывает план каждого этажа в зависимости от назначения всего здания, <...> газетный оформитель решает вопросы композиции полос в зависимости от композиции всего номера газеты» (Попов, Гуревич, 1967: 198). Кроме того, вышла монография Д. Георгиева «Архитектура на вестника» («Оформление газеты») (1971).

8 См. напр.: Жаров В. Идет «брусковая» верстка // Сов. печать. 1966. № 1.

9 «Эталон <...> 2. перен. Мерило, образец» (Ожегов С.И. Указ. соч. С. 810).

10 В книжном деле исследованием художественного конструирования книги занимались В.Н. Ляхов и др. (см.: Ляхов, 1971; Адамов, Бельчиков и др., 1971).

${ }^{11}$ Крылатый профессионализм «гвоздь номера», симоновское «был фитиль всем прочим» ит.д.

12 Оформление заголовков включает в себя следующие операции: определение гарнитуры, кегля, начертания; набора прописными или строчными; деление на строки; выключку, то есть все процедуры, предусмотренные программой верстки Adobe InDesign.

13 Неудачным оказался опыт разработки 15 вариантов стандартных макетов для каждой страницы в газете Berliner Zeitung am Abend в начале 1970 гг.

14 В настоящее время данные объекты называют комплексами (Галкин, 2008: 73-134) или блоками (Волкова, Газанджиев, Галкин и др., 2013: 68-70).

15 Ритм трактуется не как средство композиции, а как характеристика структуры.

\section{Библиография}

Адамов Е.Б. Ритмическая структура книги. М.: Книга, 1974.

Адамов Е.Б., Бельчиков И.Ф., Быкова В.Я., Гончаров А.Д. и др. Художественное конструирование и оформление книги. М.: Книга, 1971.

Волкова В.В., Газанджиев С.Г., Галкин С.И. Ситникова Е.В. и др. Дизайн периодических изданий. М.: Фак. журн. МГУ, 2013.

Галкин С.И. Материал как основа содержания номера // Визуальная коммуникация: история и актуальные проблемы современности. М.: Фак. журн. МГУ, 2012. С. 121-148.

Галкин С.И. От дизайна «вещей» - к дизайну СМИ. М.: Фак. журн. МГУ, 2010.

Галкин С.И. Оформление газеты и журнала: от элемента к системе. Общее и особенное в художественно-техническом конструировании периодических изданий. М.: Изд-во Моск. ун-та, 1984.

Галкин С.И. Художественное конструирование газеты и журнала. М.: Аспект Пресс, 2008.

Георгиев Д. Архитектура на вестника. София: Наука и изкуство, 1971.

Гончарова Н.А. Композиция и архитектоника книги // Книга как художественный предмет. Ч. 2. Формат. Цвет. Конструкция. Композиция / под ред. Е.Б. Абрамова. М.: Книга, 1990. С. 291-394. 
Ляхов В.Н. Очерки теории искусства книги. М.: Книга, 1971.

Оформление периодических изданий / под ред. А.П. Киселева. М.: Изд-во Моск. ун-та, 1988.

Попов В.В., Гуревич С.М. Производство и оформление газеты. М.: Книга, 1967.

Schröder H. (1969) Zum sozialischen Sensationbegriff. Neue Deutsche Presse 19. Beilage № 3. 